\title{
Turismo Comunitário e Desenvolvimento Local: uma revisão integrativa sobre a Acolhida na Colônia
}

\author{
Turismo Comunitario y Desarrollo Local: una revisión integrativa sobre la "Acolhida na Colônia" \\ Community Tourism and Local Development: an integrating review on "Acolhida na Colônia" \\ Felipe Borborema Cunha Lima \\ Universidade da Região de Joinville (Univille), Brasil \\ felipebcl2@hotmail.com \\ DOI: https://doi.org/10.18472/cvt.19n2.2019.1443 \\ Redalyc: http://www.redalyc.org/articulo.oa? \\ $\mathrm{id}=115460585003$
}

Yolanda Flores e Silva

Universidade do Vale do Itajai (Univali), Brasil

floresesilva.yolanda907@gmail.com

Recepção: 08 Maio 2017

Aprovação: 26 Janeiro 2019

\section{Resumo:}

Muitos países pobres são levados a acreditar no turismo convencional como um promotor do desenvolvimento. Contudo, se não direcionados às necessidades da população, pode levar à exploração humana e à segregação espacial sem melhorias reais. No final do século XX, o turismo comunitário (TC), ao adotar práticas mais sustentáveis, se contrapóe a esse modelo de turismo. Esta revisão bibliográfica de natureza integrativa objetiva apresentar a discussão brasileira sobre o TC da Associação de Agroturismo Acolhida na Colônia (AAAC). A pesquisa foi via revisão bibliográfica nas bases de dados: Scielo, Icap, Portal de Periódicos Capes, Biblioteca Virtual da USP e Biblioteca Digital Mundial. Os discursos dos autores foram analisados segundo Geertz, unindo as informações da coleta bibliográfica ao conhecimento dos autores sobre TC e AAAC. Das 100 bibliografias coletadas selecionaramse 40 trabalhos. Ao final, o estudo permitiu reconhecer o TC como um arranjo produtivo capaz de ofertar novas oportunidades de renda aos grupos tradicionais com prestação de serviços de hospedagem, alimentação e lazer em unidades familiares e criar atividades turísticas integradas à proteção ambiental e cultural.

Palavras-Chave: Turismo Comunitário, Acolhida na Colônia, Agroturismo, Comunidades Tradicionais, Desenvolvimento Local.

\section{Abstract:}

Many poor countries are led to believe in conventional tourism as a promoter of development. However, if not targeted to the needs of the population can promote human exploration, spatial segregation without real improvements. At the end of the 20th century, community tourism (TC), by adopting more sustainable practices, contrasts with this tourism model. This bibliographical review in integrative nature aims to present the Brazilian discussion on community tourism by the Association of Agritourism "Acolhida na Colônia" (AAAC). The research was via bibliographic review in the databases: Scielo, Icap, Portal of Periodicals Capes, Virtual Library of USP and World Digital Library. The authors' discourses were analyzed according to Geertz, joining the information from the collection of bibliographic data to the authors' knowledge about TC and AAAC. At the end of the study, it was possible to recognize CT as a productive arrangement capable of offering new income opportunities for traditional groups with provision of lodging, food and leisure services in family units and to create tourism activities integrated with environmental and cultural protection.

KeYworDs: Community Tourism, Acolhida na Colônia, Agritourism, Traditional Communities, Local Development.

\section{RESUMEN:}

Muchos países pobres son llevados a creer en el turismo convencional como un promotor del desarrollo. Sin embargo, si no se dirige a las necesidades de la población puede promover la explotación humana, la segregación espacial sin mejoras reales. A finales del siglo XX, el turismo comunitario (TC) al adoptar prácticas más sostenibles, se contrapone a este modelo de turismo. Esta revisión bibliográfica de naturaleza integrativa objetiva presentar la discusión brasileña sobre el TC de la Asociación de Agroturismo "Acolhida na Colônia" (AAAC). La investigación fue vía revisión bibliográfica em las bases de datos: Scielo, Icap, Portal de Periódicos Capes, Biblioteca Virtual de la USP y Biblioteca Digital Mundial. Los discursos de los autores fueron analizados según Geertz, uniendo las informaciones de la colecta bibliográfica al conocimiento de los autores sobre TC y AAAC. Al final el estudio permitió reconocer al TC como un arreglo productivo capaz de ofrecer nuevas oportunidades de ingresos para grupos tradicionales 
con prestación de servicios de hospedaje, alimentación y ocio en unidades familiares y crear actividades turísticas integradas a la protección ambiental y cultural.

Palabras Clave: Turismo Comunitario, Acolhida na Colônia, Agroturismo, Comunidades Tradicionales, Desarrollo Local.

\section{INTRODUÇÃO}

As dinâmicas que envolvem o turismo de massa ou convencional são criticadas por autores como Bursztyn, Bartholo e Delamaro (2009) que descrevem esse tipo de turismo de forma negativa, mostrando que ele pode atingir vários setores de uma comunidade, comprometendo-a, seja em nível social, ambiental ou cultural. Contudo, um novo modelo de turismo vem sendo discutido e visto como alternativa a esse modelo.

Mas, afinal, de que turismo estamos falando? Antes de tudo é importante que se perceba que o turismo pode ocorrer considerando-se várias perspectivas. Entretanto, é comum empresários e gestores de países pobres não levarem em consideração que nem todos os lugares possuem condições para ofertar um turismo sem riscos e impactos desfavoráveis, algo que pode mais prejudicar do que ajudar economicamente. É importante que se diga que muitas pessoas são levadas a acreditar no turismo como uma iniciativa que promove o desenvolvimento, o que não acontece na prática em todas as localidades em que o turismo ocorre, uma vez que apenas as atividades sólidas com grande respaldo na industrialização atuam como base para o desenvolvimento econômico (CORIOLANO et al., 2009a).

Embora muito se fale de infraestrutura e das novas oportunidades de emprego e renda que surgem com o desenvolvimento do turismo, Coriolano e colaboradores (2009a) advertem que no turismo convencional os resultados muitas vezes não favorecem a população das pequenas comunidades em função da exploração humana e segregação espacial. Como reflexo, uma grande parcela da população, além de permanecer habitando áreas inadequadas, comumente não é absorvida pelo mercado de trabalho, e quando isso acontece não conquista bem-estar e qualidade de vida, ao contrário, é cada vez mais comum observarmos, em especial jovens e crianças em atividades exaustivas em subempregos que induzem à exploração da mão de obra, prostituição ou com segregação da vida social e escolar que não conseguem vivenciar porque precisam estar trabalhando em condições precárias.

Esse tipo de turismo recebe inúmeras críticas em função dos impactos e transformações negativas que ocorrem em função de suas atividades. Como adverte Barbosa (2011), o turismo de megaempreendimentos em muitos lugares é responsável pela apropriação indevida de terras, desvalorização cultural e degradação ambiental. A autora sugere ainda que uma comunidade pode repensar a atividade turística e desenvolvê-la de forma diferenciada, organizando-se a partir de associações, que busquem beneficiar seus membros, por meio da luta pelos interesses comuns a todos, sem que para tanto seja necessário abandonar o modelo de sociedade onde estão inseridos.

O turismo, portanto, pode ser desenvolvido por dois eixos básicos. Um turismo convencional de acordo com sua posição ante o mercado econômico, seguindo as regras do capitalismo que visa essencialmente ao lucro e à acumulação de bens, ou seguir com um modelo de turismo, que, embora vise o lucro, os participantes estão inseridos em um contexto de discussão coletiva com iniciativas de organização e execução a cargo de associações/cooperativas cujos membros desejam ter no turismo uma alternativa econômica, sem que para tal se eliminem as atividades tradicionais desenvolvidas por estes no seu cotidiano de trabalho (CORIOLANO, 2006).

Sobre como o TC ocorre em uma comunidade agrícola é que trataremos neste artigo. $\mathrm{O}$ turismo realizado pela Acolhida na Colônia, que acompanhamos nos últimos 18 anos no estado de Santa Catarina, sul do Brasil, será o exemplo apresentado e discutido segundo autores brasileiros. Esta revisão bibliográfica de natureza integrativa teve por objetivo "apresentar a discussão brasileira sobre o turismo comunitário da Associação de Agroturismo Acolhida na Colônia”. No tópico a seguir os caminhos da pesquisa. 


\section{PERCURSO METODOLÓGICO}

Esta pesquisa ocorreu via revisão bibliográfica integrativa acerca da temática Turismo Comunitário (TC), de modo a apresentarmos uma síntese do conhecimento de autores brasileiros sobre o turismo comunitário em uma comunidade agrícola, tendo como exemplo o case "Acolhida na Colônia" (Acolhida na Colônia, 1999). As revisões integrativas são comuns na área da saúde, onde a síntese de vários conhecimentos ajuda na incorporação da aplicabilidade dos resultados mais significativos na prática profissional (SOUZA; SILVA; CARVALHO, 2010). No turismo esperamos obter, com pesquisas com este perfil, a possibilidade de discussão e aprendizados sobre o TC em cases consolidados como o da Acolhida na Colônia. Considerado esse contexto, a pesquisa teve como percurso metodológico os seguintes momentos e/ou etapas:

1 - Seleção, sistematização e leituras de produções bibliográficas sobre TC e o case "Acolhida na Colônia";

2 - Confirmação e atualização dos autores e bibliografias através das Bases de Dados Brasileiras: Scientific Electronic Library On-line (Scielo), Indexação Compartilhada de Periódicos (Icap), Portal de Periódicos da Coordenação de Aperfeiçoamento de Pessoal de Nível Superior (Capes), Biblioteca Virtual da Universidade de São Paulo (USP) e Biblioteca Digital Mundial;

3 - Em seguida a essas etapas, iniciamos a construção dos critérios de análise dos dados coletados. Essa etapa envolveu a leitura, transcrição das informações dos artigos científicos e da atualização realizada nas bases de dados. Os discursos dos autores foram analisados segundo Geertz (2008), unindo as informações da coleta bibliográfica ao conhecimento dos autores sobre TC e Acolhida na Colônia.

As pesquisas sobre TC e Acolhida na Colônia em língua portuguesa somam mais de 100 de autoria de profissionais ligados à docência universitária e pesquisa em Programas de Pós-Graduações em Turismo brasileiros, com formações distintas (saúde, turismo, economia, design, engenharia florestal, arquitetura, agronomia, geologia, geografia, pedagogia, entre outros).

Selecionamos 40 trabalhos com autores que se repetem sozinhos ou com coautorias em pesquisas clássicas até as mais atuais (1999 - 2016). Eles foram selecionados porque discutem em seus artigos, comunicações, dissertações e teses, os conceitos, as características e o papel do TC em comunidades tradicionais e as mudanças proporcionadas. Os trabalhos relacionados mais especificamente sobre a Acolhida na Colônia complementam essas informações mostrando uma realidade de TC que existe há 20 anos, com constantes avaliações, em uma dinâmica de atualização do seu início aos dias atuais.

\section{TURISMO COMUNITÁRIO: A PESQUISA}

Neste tópico apresentamos nossas escolhas acerca da temática "turismo comunitário" (TC), um segmento (?), modelo (?) ou alternativa (?) que se contrapõe ao turismo de massa cujas bases econômicas por vezes se fecham unicamente na perspectiva econômica com concentração de renda em uma única pessoa ou grupo empresarial. Para Maldonado e Zambrano (2006), o TC não é isento de riscos e ameaças, mesmo quando desenvolvido por comunidades que adotam o cooperativismo e as ações de solidariedade. É importante que a comunidade que se propõe a desenvolvê-lo promova debates sobre o assunto antes de iniciar a atividade e durante todo o ciclo de vida desta, a fim de salvaguardar seus interesses e minimizar os efeitos indesejáveis.

\subsection{O TURISMO COMUNITÁRIO: DO QUE ESTAMOS FALANDO?}

Guzzatti, Sampaio e Coriolano (2013) entendem que o TC surge como uma ação de resistência das comunidades rurais, pesqueiras, indígenas, quilombolas, ante o turismo de massa que se apropria e leva à descaracterização dos territórios marginalizados e menos favorecidos. Esse novo segmento, além de abrir uma série de possibilidades para a implementação de vários arranjos produtivos associados ao turismo, se 
caracteriza pela formação de redes e parcerias solidárias. No caso da "Acolhida na Colônia”, seu início se dá entre agricultores que moram em região serrana com relativo isolamento, êxodo rural e envelhecimento de sua população nos anos de 1998.

De acordo com Bursztyn, Bartholo e Delamaro (2009), o TC apresenta uma menor necessidade de infraestrutura e serviços, diminuindo os impactos no local onde é desenvolvido, tanto por modificar em menor escala o espaço como por valorizar os vínculos nos âmbitos naturais e culturais da população. A postura que permeia esse formato de turismo ocorre com relação à proteção dos bens culturais e naturais ao mesmo tempo que também oferece uma nova proposta de hospitalidade e convivência entre quem hospeda/visita.

Essa mudança de postura recebe várias denominações conforme a vocação dos territórios e populações onde ocorre, assumindo ser: comunitário, de desenvolvimento local, criativo, de experiência, solidário e/ou social. Qualquer que seja a denominação, imprime mudanças de hábitos dos visitantes e nas comunidades receptoras. Um dos reflexos mais visíveis é a formação de vários circuitos e rotas, ampliando as possibilidades de oferta de serviços e produtos aos visitantes. Exemplos como a Accueil Paysan (França), Acolhida na Colônia (Brasil) e Projecto Querença (Portugal) que se iniciaram em territórios com baixa densidade populacional, grande êxodo e envelhecimento populacional, e nesses lugares, o turismo nasceu a partir da oferta de alimentos, via o que Darolt (2012) denomina de circuitos curtos de comercialização de alimentos orgânicos, que, nos casos citados, ocorre em associação com circuitos turísticos rurais.

Maldonado e Zambrano (2006) observam que as primeiras experiências de turismo comunitário aconteceram no meio rural da América Latina, de forma isolada em pequenas comunidades, por volta da metade da década de 1980, impulsionadas por fatores de ordem econômica, social, cultural e política. No Brasil, a discussão sobre o tema surge no I Encontro Nacional de Turismo de Base Local, realizado em 1997, na cidade de São Paulo. Posteriormente, no I Seminário Internacional de Turismo Sustentável, realizado em Fortaleza em 2003, o meio acadêmico abre as portas para um debate integrado com os movimentos sociais. Dessa forma, o Turismo Comunitário passa a ser entendido como uma evolução do turismo cultural, etnoturismo, ecoturismo e agroturismo (SAMPAIO, 2008; SAMPAIO; HENRÍQUEZ; MANSUR, 2011).

Os estudos de Sansolo e Bursztyn (2009, p. 145) nos apresentam uma revisão das principais pesquisas sobre a "relação entre o turismo e as comunidades locais receptoras" e os principais conceitos utilizados para definir esse segmento, chamado de turismo comunitário, de base comunitária e / ou rural comunitário. Essa abrangência de termos utilizados no Brasil, principalmente, se relaciona com a vasta diversidade cultural e ambiental existente em nosso país com relação ao tema em questão.

Alguns países adotaram o termo turismo comunitário (TC) para designar o formato de turismo desenvolvido em comunidades tradicionais com ações realizadas de forma coletiva. Em países como a Bolívia, desde 2006 que o TC foi implementado é considerado um modelo alternativo de gestão turística, endógena e autônoma, planejado por organizações comunitárias rurais, indígenas e urbanas, como parte da diversificação econômica de seus sistemas produtivos.

$\mathrm{Na}$ Costa Rica, o TC é definido pelo Consorcio Cooperativo Red Ecoturística Nacional (Cooprena, 2008) como um turismo alternativo no meio rural, gerenciado por grupos populacionais organizados tendo como meta beneficiar a comunidade, com base na conservação e uso dos recursos locais, tanto natural como cultural.

O Equador adotou o conceito da Federação Plurinacional de Turismo Comunitário (FeptcE, 2008) onde o TC é gerenciado como uma atividade econômica solidária em uma perspectiva intercultural, com participação consensual de seus membros, proporcionando um manejo adequado dos recursos naturais e a valorização do patrimônio cultural, baseados em um princípio de equidade na distribuição dos benefícios gerados. Para a World Wild Found (WWF, 2001) o TC tem uma vocação e relação explícita com o ecoturismo em comunidade tradicionais, e, segundo eles, essas comunidades devem ter o controle substancial sobre o desenvolvimento e gestão das atividades desenvolvidas e seus benefícios.

Os conceitos brasileiros seguem a mesma linha de raciocínio, agregando a discussão sobre empreendedorismo comunitário e intercâmbio cultural. Para a Rede Brasileira de Turismo Solidário e 
Comunitário (TURISOL, 2008), o TC é uma forma de organização empresarial sustentada em um território por meio da autogestão dos recursos comunitários e particulares com práticas democráticas e solidárias no trabalho e na distribuição dos benefícios gerados mediante prestação de serviços visando o encontro cultural entre a comunidade e o visitante. O TC para a Rede Brasileira de Turismo Comunitário (TUCUM, 2008) é aquele no qual as populações locais possuem o controle efetivo sobre o seu desenvolvimento e gestão, e está baseado na gestão comunitária familiar das infraestruturas e serviços turísticos, no respeito ao meio ambiente, na valorização da cultura local e na economia solidária.

Em Portugal tivemos pouca bibliografia portuguesa que discuta e descreva o TC realizado principalmente nas regióes serranas e/ou interioranas. Encontramos e lemos acerca de experiências de Ecoturismo, Turismo Gastronômico e Turismo Cultural com vertente comunitária que associa os discursos e conceitos do Turismo Criativo e de Experiência a atividades realizadas em comunidades tradicionais rurais e/ou pesqueiras. Contudo, de 2014 a 2018, trabalhos dos autores realizados na Universidade do Algarve, geraram alguns estudos sobre experiências do TC no Algarve, mas as pesquisas realizadas demonstram que o conceito de comunidade na gestão do turismo tem diferenças com relação aos debates realizados por outros autores brasileiros (LIMA; SILVA, 2016; SILVA, 2013; SILVA; LIMA; CHRISTOFFOLI, 2016; SILVA; LIMA, 2016; SILVA; SILVA, 2016, 2015).

Repassando as escolhas que fizemos acerca das discussões sobre TC, assumimos que as reflexões de Coriolano e colaboradores (2009a) são as que mais refletem a experiência da Associação de Agroturismo Acolhida na Colônia (AAAC), descrita como exemplo neste artigo. A AAAC promotora do agroturismo na cidade de Santa Rosa de Lima, em Santa Catarina, possui e realiza um TC de forma associativa, planejada e controlada pela comunidade, mediante uma gestão participativa e integrada a arranjos produtivos locais. A associação, formada por agricultores familiares, mantém o controle efetivo sobre as terras e a exploração do turismo, com fortalecimento das atividades econômicas preexistentes como a agricultura, pesca e artesanato. Evidenciam-se também ações que procuram proteger as propriedades dos residentes, a geração de trabalho, valorização dos empreendimentos locais e inserção de jovens e mulheres no processo (GUZZATTI, 2003; GUZZATTI, 2010; LIMA, 2009).

Independentemente da denominação adotada, Irving (2009) observa que atividades turísticas com as características do TC estão em desenvolvimento em vários países, e não obstante os problemas relacionados ao conceito, adverte que o engajamento e a participação efetiva da comunidade em projetos dessa natureza ainda configuram um desafio para muitos e uma realidade para poucos.

Para Parent, Klein e Jolin (2009), embora ocorram muitos problemas na organização do TC, a necessidade de superar as adversidades nas pequenas comunidades faz com que esse formato de turismo seja visto não apenas como alternativo, mas, também, como uma possibilidade de turismo mais permanente e de longa duração. O TC, portanto, tem por base e princípios assumir um formato onde a acumulação de bens não é o mais importante, sendo o contexto geral mais significativo, algo descrito por Silva, Lima e Christoffoli (2016) como outro modo de fazer turismo, ou seja, existe equilíbrio das atividades turísticas associando desenvolvimento econômico, proteção ambiental e satisfação de turistas e residentes em uma estratégia de gestão familiar que se aperfeiçoa a médio e longo prazo.

\subsection{REDES ASSOCIATIVAS E O TURISMO COMUNITÁRIO}

A estratégia mais visível no TC é a formação de grupos, associações e cooperativas para defesa e luta em prol de um objetivo comum. Para Singer (2003), o associativismo denomina toda ação coletiva alicerçada em uma modalidade qualificada de cooperação, ou seja, aquela que favorece a cooperação sem desconsiderar as coações impostas pela busca de competitividade sistêmica ou territorial. Contudo, tal estratégia se fortalece ainda mais quando se utiliza esse princípio para as próprias associações e, com isso, se formam as redes. A Acolhida na Colônia, seguindo o exemplo da Accueil Paysan, na França, criou uma associação que pudesse 
ser o espaço de discussão do tipo de organização que deveriam seguir e ao mesmo tempo ser o lugar onde se fariam as tramitações jurídicas voltadas para as questões relativas às tributações (impostos) e tramitações sanitárias, grandes "gargalos" desse formato de proposta (LIMA; SILVA, 2016).

Para Maldonado e Zambrano (2006), as redes associativas são entendidas como: novas abordagens de interação econômica, organizações de produção e desenvolvimento de empresas comunitárias, que se originam da tentativa de atingir níveis mais elevados de eficiência econômica e competitividade do que os alcançados isoladamente. As redes no TC são vistas pela maioria dos autores como uma poderosa conexão do turismo com parceiros que interligam recursos socioculturais, econômicos e ambientais.

Embora fazer parte de uma rede seja algo positivo e estimule de maneira eficaz a atividade turística, Saxena e Ilbery (2008) nos alertam que isso não significa estar imune aos problemas e às fragilidades, ao contrário, os autores apontam três problemas que surgem ao adotar esse formato: o baixo nível de integração das redes de empresas locais com o planejamento estratégico regional; problemas de competitividade pela precária ligação dos atores locais via ações coordenadas com o marketing; e localismo defensivo e disputa de poder nas bases locais. No caso da Acolhida na Colônia, seus associados tiveram que se capacitar para compreender o processo que envolve trabalhar como pequenos empreendedores em uma atividade cujas bases são muito mais econômicas e raramente sociais.

Guzzatti (2010) nos revela que embora sejam identificados vários resultados positivos na Acolhida na Colônia, também foram evidenciados impactos negativos, tais como: incompatibilidade com outras atividades desenvolvidas no local, pouca infraestrutura, que no médio prazo pode gerar impacto negativo na imagem divulgada, diminuição da importância das atividades agropecuárias, bem como outros tipos de transtornos provocados pela presença de pessoas estranhas à comunidade incidindo no aumento de certos tipos de conflitos, tais como o uso de drogas ilegais, entre outros elementos.

Situações semelhantes foram relatadas por Lima (2009) com relação às atividades do TC na Acolhida na Colônia, contudo, o fator mais preocupante citado foi a falta de um envolvimento de membros importantes da comunidade em todo o processo de decisão, o que tornava mais difícil integrar o planejamento da atividade local com as instâncias regionais. Essa integração é importante no sentido de influenciar a dimensão social de um turismo que busca a sustentabilidade em relação aos stakeholders da comunidade. Covas e Covas (2010) apontam, também, o fato de a zona rural ser um ambiente regulatório que pode criar barreiras ao desenvolvimento. Para os autores, o excesso de zelo regulamentar e a burocracia na abertura de pequenas empresas, bem como a cobrança de impostos de igual valor para grandes e pequenos empresários são alguns dos problemas que devem ser considerados.

A complexidade envolvendo os novos estilos produtivos encontrados no turismo em espaço rural, para Lima (2009), exige uma maior reflexão no processo como um todo, principalmente os aspectos relacionados à integração das comunidades. Por entender que o turismo comunitário, desenvolvido pela comunidade e fortalecido mediante alianças e parcerias com outras associações, está sujeito a riscos e deficiências, Maldonado e Zambrano (2006, p. 25-26) apresentam no "Manual del Facilitador de TC" os principais riscos da atividade:

1- Oferta dispersa e fragmentada, carente de estruturas e mecanismos regulares de cooperação interna para organizá-la e externa para potencializá-la. Apesar das vantagens com as parceiras serem percebidas, os esforços empreendidos ainda são incipientes e pouco sistemáticos;

2- Escassa diversificação dos produtos turísticos cujos componentes são baseados exclusivamente em fatores naturais e herdados. Existe potencial e vontade para empreender inovações que superem o mimetismo predominante;

3- Gestão profissional limitada, tanto operacional como gerencial dos negócios; as tendências e o funcionamento da indústria do turismo são desconhecidos. As aspirações das comunidades de acesso a serviços de informação e capacitação permanecem amplamente insatisfatórias;

4- Qualidade heterogênea dos serviços, com predominância de qualidade média e baixa. A competência aguda com outras empresas tende a resolver-se somente em curto prazo através da baixa de preços;

5- Posicionamento incerto e imagem pouco divulgada do turismo comunitário em mercados e segmentos dinâmicos: a promoção e comercialização são realizadas, geralmente, por meios rudimentares, individuais e diretos; 
6- Deficiência dos mecanismos de informação, comunicação e organização comercial: a fraca representação e capacidade para negociação com outros agentes da cadeia turística não permite a tomada de decisões estratégicas, além do horizonte diário;

7- Participação marginal ou subordinada de mulheres e suas associações na concepção e condução de projetos turísticos e, consequentemente, na captação de benefícios;

8- Déficit notável de serviços públicos: rodovias, eletricidade, água potável, saneamento ambiental e esgoto, comunicações e sinalização turística. As comunidades não são capazes de cobrir esses custos; isso é responsabilidade dos governos locais ou nacionais.

Bursztyn, Bartholo e Delamaro (2009) evidenciam que muito embora essas comunidades possuam problemas semelhantes e busquem o TC como propulsor do desenvolvimento local, a atividade turística não possui um formato padrão a ser adotado, podendo ser executada de diferentes formatos, nos quais podem ser evidenciadas estruturas e objetos, contextos e valores culturais relativos ao local. Esse processo, portanto, representa para a comunidade um elemento de descoberta, pois para sua viabilização, os seus membros devem discutir o que querem e o que podem fazer para o desenvolvimento das pessoas e do local. Coriolano (2009b) retrata essa situação como uma experiência na qual as comunidades experimentam novas formas de produção dos serviços turísticos, de maneira criativa, estimulados pelo compromisso e pela solidariedade, o que os distancia da padronização do formato turístico tradicional.

\subsection{A ACOLHIDA NA COLÔNIA: DE 1998 - 2016}

No sul do Brasil, a implantação de atividades turísticas no formato de Turismo Comunitário (TC) ocorreu oficialmente em meio rural no estado de Santa Catarina no formato de Agroturismo em 1998. O Centro de Estudos e Promoção da Agricultura de Grupo (Cepagro) e a Associação dos Agricultores das Encostas da Serra Geral (Agreco), entidades ligadas à agricultura familiar, foram importantes organizações populares que auxiliaram na condução de construção do TC nos municípios de Santa Rosa de Lima (sede do processo), Rancho Queimado, Anitápolis, Rio Fortuna e Gravatal (GUZZATTI, 2003).

O Cepagro e a Agreco atuam com famílias de agricultores cujas bases de ação é a agricultura de subsistência agroecológica. Embora os agricultores envolvidos tivessem dúvidas quanto às vocações territoriais dos grupos que ali habitavam, para a oferta de atividades turísticas na regiáo, a agrônoma Thaise Guzzatti, interessada em oferecer novas perspectivas ao meio agrícola de reforço à economia familiar, trouxe para o grupo gestor do Cepagro e AGRECO o TC no formato agroturismo da 'Accueil Paysan' da "Accueil Paysan”. Essa organização francesa mostra ser possível que um agricultor continue suas atividades agrícolas aliando hospedagem com a oferta de alimentação orgânica. É importante ressaltar, que, historicamente, coube ao folósofo e professor da Universidade Federal de Santa Catarina, Wilson Schimdt (falecido em 2018), a iniciativa de promover a hospedagem de citadinos nas propriedades dos agricultores de Santa Rosa de Lima de 1995 a 1997. Guzzatti (2003) deu continuidade a esse processo, trazendo a marca francesa Accueil Paysan, elaborando uma proposta de alojamento rural que se adaptasse à realidade catarinense (ARNHOLD JÚNIOR, 2006; LIMA, 2009; SILVA et al., 2012; ULLER, 2005).

O fato de existir uma demanda, com a vinda de técnicos, agricultores e pesquisadores interessados nos aprendizados ligados à agroecologia associada ao turismo, fortaleceu a ideia de que se precisava criar uma estrutura que pudesse receber esses convidados, sem com isso interromper as ações relacionadas à prática do cultivo e à colheita. A proposta elaborada para implantação de um programa de organização do TC / Agroturismo na região inicia-se em 1996 com o encaminhamento de um projeto ao Ministério de Desenvolvimento Agrário / Secretaria de Agricultura Familiar / e Programa Nacional de Fortalecimento da Agricultura Familiar. O projeto tinha por base a implantação do TC no formato Agroturismo com várias etapas para sua realização: mobilização e sensibilização da comunidade; diagnóstico das propriedades rurais; formação de uma associação de agroturismo que pudesse estabelecer as normas de participação dos 
envolvidos; organização de capacitações voltadas para o resgate e a preservação da cultura e meio ambiente da região (SILVA; LIMA; OLIVEIRA, 2009).

Com a aprovação do projeto, em 1998, iniciaram-se as ações de preparação para a implantação do "turismo" dos agricultores familiares com várias reuniões com a comunidade local para que se discutisse a abrangência territorial da proposta. Desde o início, a ideia era quebrar os limites territoriais de circulação das pessoas, visto existir uma vasta relação de possibilidades de consórcios temáticos entre os municípios. Entretanto, a organização do TC não é fácil. As propostas de TC no Brasil e América Latina ocorrem em países pobres e periféricos. Barbosa (2011) entende que uma das vantagens, é que nesses países, onde existe uma maior exploração da mão de obra, é que é possível que os grupos minoritários se organizem e assumam o controle e a gestão da atividade e, para tal, utilizam mecanismos operacionais, como a criação de cooperativas e associações.

Em alguns lugares, esse processo não se dá de forma simples e pacífica, ao contrário, pode ser considerado uma luta de classes, uma luta étnica ou uma luta por território contra o avanço do turismo empresarial internacional. A mobilização das comunidades possibilita a resistência e o questionamento dos rumos do desenvolvimento turístico no território em que se estabelecem. Esses grupos se tornam as personagens centrais desse embate, tendo que recorrer muitas vezes a longas reuniões com o poder público e representantes do trade turístico, até situações mais extremas como a manifestação pública com protestos, abaixo-assinado, e divulgação na imprensa (BARBOSA, 2011).

Nos estudos realizados por Guzzatti (2010) e Mendonça e Irving (2004), a motivação para a organização do TC no Brasil, principalmente, foi a luta pela posse da terra, o direito ao uso sustentável dos recursos naturais, contra a expulsão da população para guetos e favelas nas cidades maiores e até mesmo em defesa da vida das pessoas envolvidas. A organização comunitária nascida com essas bases se fortalece à medida que se une em defesa de causas próprias, sendo responsáveis pela formação de associações comunitárias, cujo papel fundamental é a luta e resistência dos mais pobres contra a elite e a falta de políticas públicas que se voltem para suas necessidades (SILVA; SILVA, 2015).

Para Bartholo (2009, p. 51), o TC consegue não apenas oferecer perspectiva de trabalho e renda como também é "um meio para dar visibilidade aos conflitos". Para garantir essa maior exposição e um impacto positivo perante a sociedade, muitos grupos marginalizados de comunidades tradicionais se unem a outros grupos ligados a universidades e organizações não governamentais de modo a promover articulações em redes e parcerias que podem chegar a abrangência internacional (BARBOSA, 2011; SILVA; SILVA, 2015).

No caso da Acolhida na Colônia, esta tem como parceiros universidades públicas e privadas no estado brasileiro em que tem sua base. Tem também a credibilidade de Ministérios, como o do Turismo e do Desenvolvimento Agrário brasileiros, bem como de órgãos internacionais, como as Nações Unidas via Organização Mundial do Turismo (OMT), Organização das Nações Unidas para a Alimentação (FAO) e Programa das Nações Unidas para o Desenvolvimento (Pnud). A Accueil Paysan se revelou nos últimos anos uma parceira importante, visto que lançou no mundo sua filial brasileira, hoje uma referência para o Brasil e para a própria França (GUZZATTI; SAMPAIO; CORIOLANO, 2013).

O TC possui também como característica a integração de vivências, serviços de hospedagem e de alimentação, as questões ambientais, educação e saúde. Em outras palavras, o TC "é uma proposta de desenvolvimento territorial sistêmico (sustentável) a partir da própria comunidade" (SAMPAIO; ZECHNER; HENRÍQUEZ, 2008, p. 10) com possibilidade de buscar desenvolvimento em outros segmentos da sociedade.

A convivência ética e responsável dos visitantes para com seus anfitriões pode impulsionar o ganho coletivo mediante o comércio justo, via feiras de trocas e/ou vendas solidárias, sendo denominadas de comércio ecossocioeconômicos. Desse modo, surge uma nova relação, mais livre e direta, integrando produtores que não se encaixam no modelo econômico padrão, e, portanto, em vias de marginalização, empobrecimento e exclusão. Ao mesmo tempo é possível encontrar consumidores solidários, dispostos a colaborar, mesmo que 
para tal paguem um preço mais alto no começo do processo. Essa relação é pautada no respeito mútuo, na intenção de manter uma parceria de longo prazo, pois é observado um ganho mais justo e digno para todos (PLATAFORMA KOMYUNITI, 2005).

Para Silva e Silva (2015), o TC sustentável não leva em consideração apenas a satisfação dos anseios da comunidade que o desenvolve, muito pelo contrário, também visa atender e suprir as necessidades dos turistas, sem que para tal sacrifique a comunidade receptora ou coloque em risco a capacidade das gerações futuras de atender às suas necessidades. Em outras palavras, é um formato de turismo que visa à sustentabilidade por meio de uma conduta ecologicamente correta, com geração de emprego e renda, associando o desenvolvimento econômico do local com o equilíbrio socioambiental.

Para que exista toda uma gama de fatores que favoreçam esses resultados, alguns princípios se fazem necessários enquanto estratégias de ação que envolvem iniciativas de trabalho que surjam a partir das necessidades da população moradora. Esses princípios foram aperfeiçoados pela Accueil Paysan e Acolhida na Colônia quando elaboraram seu "Caderno de Normas" (Acolhida na Colônia, 1999), seguindo de certa forma os princípios defendidos por Carmo (1999):

Princípio da Participação: participação da população residente na construção e desenvolvimento da atividade; Princípio da Cooperação: desenvolvida e criada pelos membros da comunidade com propostas de parcerias associativas e redes; Princípio da Autossustentação: a comunidade deve ser capaz de manter o controle e evitar possíveis alterações e influências externas; Princípio da Universalidade: as ações comunitárias e os resultados devem ser evidenciados pelo grupo que a executa e não apenas por parte deste.

Irving (2009) descreve também alguns princípios do TC tendo como base a proposta de Carmo (1999), como, por exemplo: o TC necessita ter uma base endógena, participação e protagonismo da população local, escala limitada de atividades turísticas e impactos controlados, geração de benefícios diretos, afirmação cultural e o encontro como condição essencial. Para a autora, é necessária uma base endógena no que tange à iniciativa para o desenvolvimento do TC, pois o processo como um todo é fruto da relação direta de dependência e sobrevivência material e simbólica dos grupos da comunidade. É admitido um indutor externo, mas a real motivação para o desenvolvimento do turismo, só é evidenciado no protagonismo social que é resultado do sentimento de pertença e do poder de influência nos processos de decisão do grupo. Outro ponto que ela defende trata da participação e protagonismo social no planejamento, implementação e avaliação do projeto, que confere sustentabilidade à proposta e garante uma condução ética no que se refere ao patrimônio natural e cultural do local.

Para Silva, Lima e Christoffoli (2016), como os projetos comunitários são desenvolvidos observando os recursos locais, as potencialidades e as restrições da comunidade, é essencial que seja desenvolvido em escala limitada, contrapondo à macroestrutura do turismo de massa e, dessa forma, ajudando a minimizar e a controlar os impactos sociais e ambientais. Outro ponto apontado é que o TC deve gerar benefícios diretos à população local em sua totalidade e não apenas para parte dela. Sobre a afirmação cultural e a interculturalidade, esta trata da questão como sendo voltada à valorização da cultura local, agindo com o intento de afirmação da identidade e pertencimento por meio da coesão social. O elemento final da análise, o encontro, retratado como condição essencial, é a grande experiência em si do TC, quando visitante e visitado atuam como agentes, sujeitos e objetos no processo, possibilitando o compartilhamento de ideias e aprendizado mútuo, proveniente do intercâmbio real entre os sujeitos.

Considerando todos esses pontos, percebe-se que o TC é uma tomada de poder, uma forma que as comunidades tradicionais têm de ficar à frente de uma atividade que estimule o desenvolvimento local, independente do grau de empobrecimento e descaracterização que se encontre, rompendo as regras e normas impostas pela sociedade urbana industrial que estimula e limita as ações de todos em um padrão materialistaconsumista (SAMPAIO, 2005). A partir desse viés, a dinâmica do turismo comunitário pode ser vista como um processo de mão dupla: 
Se por um lado, o turismo comunitário surge como reivindicação das comunidades para que estejam inseridas na cadeia produtiva do turismo, podendo participar e se beneficiar da atividade, por outro lado, o turismo comunitário encontra espaço de expansão pela tomada de consciência de que lazer e turismo podem ser associados à prática de responsabilidade social (GUZZATTI; SAMPAIO; CORIOLANO, 2013, p. 96).

Ou seja, não se trata apenas de acolher o visitante e satisfazer seus desejos, toda a atividade está baseada no intercâmbio de experiências, na convivência das pessoas, o que para Sampaio (2010) pode ser entendido como uma troca solidária, que, além de preservar e resguardar a cultura e as tradições de um povo, se caracteriza também por se afastar do interesse calculado tão presente no modelo urbano-consumista. Essa política é algo que a Acolhida na Colônia tem como regra. As experiências são parte do que consideram ganhos do TC (GUZZATTI, 2010).

\section{CONSIDERAÇÕES FINAIS}

O estudo permitiu reconhecer nos discursos dos autores uma integração de pensamentos quanto ao conceito de Turismo Comunitário, enquanto um arranjo produtivo capaz de ofertar novas oportunidades de renda para grupos tradicionais como o de agricultores familiares que atuam no cultivo de alimentos biológicos e/ ou orgânicos. De uma forma geral, as pesquisas demonstram ser esse um modelo que permite, por meio da prestação de serviços de hospedagem, alimentação e lazer nas unidades familiares, criar atividades turísticas integradas com a proteção ambiental, a salvaguarda cultural e, principalmente, ações realizadas mediante a cooperação associativa entre uma população tradicional (agricultores, pescadores, indígenas e grupos extrativistas) e turistas, estes vistos como parceiros.

As pesquisas realizadas com os autores selecionados nesta revisão integrada demonstram que modelos de TC, como o da Acolhida na Colônia, nascem em países onde a agricultura patronal e outros meios de subsistência de grupos étnicos minoritários não atendem às necessidades dos grupos que vivem vulneráveis à fome, pobreza e problemas relacionados às violências estruturais (falta de terra, expulsão para os centros urbano-industriais, cultivos com agrotóxicos, etc.).

Nesse sentido, o TC, segundo todos os autores pesquisados, consegue ser uma opção de geração de trabalho e renda em comunidades tradicionais, trazendo desenvolvimento de base local, associado à valorização das atividades rurais cotidianas e modos de vida de agricultores. Possibilita a troca de conhecimentos entre anfitriões e turistas, bem como atrai o interesse de pessoas mais jovens porque oferece oportunidades de trabalho onde estão seus familiares e amigos.

Ressaltamos que no caso da Acolhida na Colônia, os primeiros municípios a participarem da proposta de turismo puderam ofertar, com apoio das universidades e outras organizações, várias capacitações aos agricultores e familiares, relacionadas a atividades diversas. Esses momentos de capacitação eram voltados para culinária, higiene sanitária, decoração e organização dos espaços de hospedagem, com a criação de oferta de produtos e serviços conhecidos culturalmente, mas, que antes estes não tinham como ofertar e/ou usufruir em função da fal ta de tempo, dinheiro e disposição física. Ainda que o turismo tenha trazido outras obrigações laborais, à medida que foram aprendendo e detendo distintos conhecimentos, os agricultores entenderam inclusive que precisavam de aprendizados ligados à gestão financeira e o direito ao ócio e lazer tanto quanto os turistas que os visitam.

Saúde, bem-estar, qualidade de vida, espaços de moradia confortáveis e belos, terras cultivadas sem venenos, possibilidade de viver no território que nasceu ou naquele da sua escolha, um melhor futuro para os jovens, seja na terra em que associa agricultura e turismo ou em outros lugares, essa é a proposta do TC apresentada por todos os autores. Ainda que os riscos existam, fica claro que os impactos negativos podem ser discutidos e administrados. Já os impactos positivos podem ser ampliados e até transformados, mas não extintos. $\mathrm{O}$ princípio de TC que parece nortear o discurso dos autores, deixa claro que todo o processo de organização se revela forte porque tem por base a solidariedade, o viver ético e a participação ativa de anfitriões e turistas. 


\section{REFERÊNCIAS}

ACOLHIDA NA COLÔNIA. Estatuto da Associação de Agroturismo Acolhida na Colônia. Santa Rosa de Lima: AAAC, 1999.

ARNHOLD JÚNIOR, M. Turismo rural ético: o agroturismo em Santa Rosa de Lima - SC. Dissertação. (Mestrado em Turismo e Hotelaria) - Universidade do Vale do Itajaí, Balneário Camboriú, 2006.

BARBOSA, L. M. Redes de territórios solidários do turismo comunitário: políticas para o desenvolvimento local no Ceará. Dissertação de Mestrado. Universidade Estadual do Ceará, Fortaleza. 2011.

BARTHOLO, R. Sobre o sentido da proximidade: implicações para um turismo de base comunitária. In: BARTHOLO, R.; SANSOLO, D. G.; BURSZTYN, I. (Org.) Turismo de base comunitária: diversidade de olhares e experiências brasileiras. Letra e Imagem, Rio de Janeiro. 2009.

BURSZTYN, I.; BARTHOLO, R.; DELAMARO, M. Turismo Para Quem? Sobre caminhos de desenvolvimento e alternativas para o turismo no Brasil. In: BARTHOLO, R.; SANSOLO, D. G.; BURSZTYN, I. Turismo de base comunitária: diversidade de olhares e experiências brasileiras. Letra e Imagem, Rio de Janeiro. 2009.

CARMO, H. Desenvolvimento comunitário. Universidade Aberta, Lisboa. 1999.

COOPRENA. Consorcio Cooperativo da Red Ecoturística Nacional. Experiencias de turismo rural comunitário em Costa Rica. In: II INTERNATIONAL SEMINAR ON SUSTAINABLE TOURISM - ISST / REN, Fortaleza. 2008.

CORIOLANO, L. N. M. T. O turismo nos discursos, nas políticas e no combate à pobreza. Annablume, São Paulo. 2006.

. O Turismo Comunitário no Nordeste Brasileiro. In: BARTHOLO, R.; SANSOLO, D. G.; BURSZTYN, I. (Org.). Turismo de Base Comunitária: experiências brasileiras. Letra e Imagem, Rio de Janeiro. $2009 \mathrm{~b}$.

CORIOLANO, L. N. M. T. et al. Arranjos produtivos locais do turismo comunitário: atores e cenários em mudança. Fortaleza: Ed. Uece, 2009a. 312 p.

COVAS, A.; COVAS, M. das M. Ruralidades (V) - Modernização Ecológica, Serviços Ecossistêmicos e Riscos Globais: a ruralidade do nosso tempo. Edições da Universidade do Algarve, Faro. 2010.

DAROLT, M. R. Conexão ecológica: novas relações entre agricultores e consumidores. Iapar, Londrina. 2012.

FEPTCE. Federação Plurinacional de Turismo Comunitário. El Turismo comunitário baseado en la cosmovision andina de Sumak Kawsay. In: II INTERNATIONAL SEMINAR ON SUSTAINABLE TOURISM - ISST / REN, Fortaleza. 2008.

GEERTZ, C. A interpretação das culturas. Rio de Janeiro: LTC, 2008.

GUZZATTI, C. T. O agroturismo como instrumento de desenvolvimento rural: sistematização e análise das estratégias utilizadas para a implantação de um programa de agroturismo nas encostas da Serra Geral. Dissertação (Mestrado em Engenharia de Produção) - Universidade Federal de Santa Catarina, Florianópolis. 2003.

O agroturismo elemento dinamizador na construção de territórios rurais: o caso da Associação de Agroturismo Acolhida na Colônia em Santa Rosa de Lima (SC). Tese (Doutorado em Geografia) - Universidade Federal de Santa Catarina, Florianópolis. 2010.

GUZZATTI, C. T. O agroturismo como instrumento de desenvolvimento rural: sistematização e análise das estratégias utilizadas para a implantação de um programa de agroturismo nas encostas da Serra Geral. Dissertação (Mestrado em Engenharia de Produção) - Universidade Federal de Santa Catarina, Florianópolis. 2003.

IRVING, M. A. Reinventando a Reflexão sobre Turismo de Base Comunitária: inovar é possível? In: BARTHOLO, R.; SANSOLO, D. G.; BURSZTYN, I. Turismo de base comunitária: diversidade de olhares e experiências brasileiras. Letra e Imagem, Rio de Janeiro. 2009.

LIMA, F. B. C. O agroturismo em Santa Rosa de Lima - SC: um estudo dos discursos midiáticos e suas influências na gestão da atividade. Dissertação. (Mestrado em Turismo e Hotelaria) - Universidade do Vale do Itajaí, Balneário Camboriú. 2009. 
Felipe Borborema Cunha lima, et al. Turismo Comunitário e Desenvolvimento Local: uma revisão integ...

LIMA, F. B. C.; SILVA, Y. F. e. Project Querença and Creative Tourism: visibility and local development of a village in the rural Algarve. e-Review of Tourism Research, v. 13, n. (5/6), p. 25-40. 2016.

MALDONADO, C.; ZAMBRANO, D. Negócios turísticos com comunidades: manual del facilitador. Genebra: OIT 2006.

MENDONÇA, T. C.; IRVING, M. de A. Turismo de base comunitária: a participação como prática no desenvolvimento de projetos turísticos no Brasil - Prainha do Canto Verde, Beberibe (CE). Caderno Virtual de Turismo, v. 4, n. 4, p. 1 -22, 2004.

PARENT, S.; KLEIN, J. L.; JOLIN, L. Le Développement Communautaire Local et le Tourisme Communautaire: une analyse conceptuelle comparative. Journal for Communication Studies, v. 4, n. 1, p. 73-89. 2009.

PLATAFORMA KOMYUNITI. Cooperativa comercio justo Chile. Disponível em: . Acesso em: 16 jul. 2016.

SAMPAIO, C. C.; HENRIQUEZ, C.; MANSUR, C. (Org.). Turismo comunitário, solidário, sustentável: da crítica às ideias e das ideias à prática. Blumenau: Edifurb, 2011.

SAMPAIO, C. A. C.; ZECHNER, T. C.; HENRÍQUEZ, C. Pensando o Conceito de Turismo Comunitário a partir de Experiências Brasileiras, Chilenas e Costarriquenha. In: II SEMINÁRIO INTERNACIONAL DE TURISMO SUSTENTÁVEL (SITS). Anais... Fortaleza, Brasil. 2008.

SAMPAIO, C. A. C. Gestão que privilegia outra economia: ecossocioeconomia das organizações. Blumenau: Edifurb, 2010.

Pensando o conceito de turismo de base comunitária. In: V SEMINÁRIO DA ASSOCIAÇÃO DE PESQUISA E PÓS-GRADUAÇÃO EM TURISMO - ANPTUR. Belo Horizonte, 2008.

Turismo como fenômeno humano: princípios para se pensar a socioeconomia. Santa Cruz do Sul: Edunisc. 2005.

SANSOLO, D. G.; BURSZTYN, I. Turismo de Base Comunitária: potencialidades no espaço rural brasileiro. In: BARTHOLO, R.; SANSOLO, D. G.; BURSZTYN, I. Turismo de base comunitária: diversidade de olhares e experiências brasileiras. Rio de Janeiro. Brasil: Letra e Imagem, 2009.

SAXENA, G.; ILBERY, B. Integrated rural tourism: a border case study. Annals of Tourism Research, v. 35, n. 1, p. 233-254. 2008.

SILVA, Y. F. Turismo Comunitário: contribuições para a diminuição da desertificação populacional e desenvolvimento local no sul do Brasil e Portugal. 30f. Projeto de Pesquisa - Faculdade de Economia / PósDoutoramento em Turismo - Universidade do Algarve, Faro, 2013.

SILVA, Y. F.; CUNHA LIMA, F. B. Turismo criativo em uma aldeia do Algarve: experiência e desenvolvimento local sustentável. In: DESAFIOS, ESTRATÉGIAS E TENDÊNCIAS EM TURISMO E HOTELARIA. Gráfica Comercial Loulé / UALG, Loulé (p. 385-401), 2016.

SILVA, Y. F.; CUNHA LIMA, F. B.; CHRISTOFFOLI, A. R. Turismo rural comunitário: gestión familiar y estrategias de consolidación en el estado de Santa Catarina (Brasil). Estudios y Perspectivas en Turismo, v. 25, n. 4, p. 1 - 15. 2016.

SILVA, Y. F.; CUNHA LIMA, F. B.; OLIVEIRA, L. S. Um olhar sobre os discursos acadêmicos e midiáticos do agroturismo em Santa Rosa de Lima/SC. Revista Brasileira de Pesquisa em Turismo, v. 4, n. 3, p. 41-53. 2009.

SILVA, Y. F.; SILVA, J. A. Community based tourism: an overview of local development. In: INTERNATIONAL CONFERENCE ON EMERGING TOURISM DESTINATIONS (ICETD - 2016), East Timor: ICETD, 2016.

. Projeto Querença: redes e parcerias como base para o desenvolvimento local e um turismo comunitário e criativo na aldeia de Querença - Portugal. Revista Turismo \& Desenvolvimento (On-line), v. 6, n. 2, p. 83-95. 2015.

SILVA, Y. F. et al. Organizações comunitárias e parcerias solidárias no turismo rural em Santa Catarina. In: VIII CITURDES: TURISMO RURAL EM TEMPOS DE NOVAS RURALIDADES. Anais... Chaves: Utad, 2012.

SINGER, P. A outra economia. Porto Alegre: Editores Veraz. 2003. 
SOUZA, M. T. de; SILVA, M. D. da; CARVALHO, R. de. Revisão integrativa: o que é e como fazer. Einstein, São Paulo, v. 8, n. 1, p. 102-106, jun., 2010.

TUCUM. Rede Brasileira de Turismo Comunitário. II INTERNATIONAL SEMINAR ON SUSTAINABLE TOURISM - ISST / REN, Fortaleza. 2008.

TURISOL. Rede Brasileira de Turismo Solidário e Comunitário. 2008. Disponível em: . Acesso em: jul. 2016.

ULLER, C. D. O agroturismo de Santa Rosa de Lima-SC: características e singularidades da hospedagem familiar. Dissertação (Mestrado em Turismo e Hotelaria) - Universidade do Vale do Itajaí, Balneário Camboriú. 2005.

WWF. Guidelines for community-based ecotourism development. 2001. Disponível em: . Acesso em: jul. 2016.

\section{Notas}

[1] Este artigo é uma versão ampliada de comunicação oral apresentada no XIII ANPTUR, em São Paulo, 2016. 